\title{
RANCANG BANGUN SISTEM PENGADAAN JASA WEDDING ORGANIZER SALON ARJUNA SRIKANDI BERBASIS WEB
}

\author{
Karlina \\ Program Studi Informatika, Fakulta Teknik Ilmu Komputer, Universitas Indraprasta PGRI \\ Jalan Raya Tengah No 80, Kelurahan Gedong, Pasar Rebo, Jakarta Timur \\ tantowilyna@gmail.com
}

\begin{abstract}
Abstrak
Wedding Organizer adalah suatu jasa yang berfungsi secara pribadi membantu calon pengantin dan keluarga perencanaan dan supervisi pelaksanaan rangkaian acara pesta pernikahan sesuai dengan jadwal dan budget yang telah ditetapkan. Sistem informasi wedding organizer yang dibuat dengan manfaat teknologi informasi berbasis web, dengan tujuan untuk memperluas area promosi dan penjualan paket pernikahan dan mempermudah proses pesanannya. Sistem pengadaan jasa wedding organizer ini menggunakan bahasa pemograman $P H P$ dan $M Y S Q L$, metode yang digunakan dalam pengembangan sistem ini yaitu menggunakan metode prototyping yang terdiri dari analisa, design, pembuatan aplikasi, evaluasi dan hasil. Sistem informasi wedding organizer sangat membeantu bagi orang-orang yang tidak mau repot dengan masalah perencanaan pernikahan mereka. Dengan perkembangannya teknologi sekarang ini wedding organizer sudah mulai berpindah dari proses online yaitu sistem informasi wedding organizer berbasis web.
\end{abstract}

Kata Kunci: Sistem Pengadaan Jasa, Wedding Organizer, Web, PHP, Database MySQL

\begin{abstract}
Wedding Organizer is a service that works personally to help prospective brides and family planning and supervising the implementation of wedding ceremony in accordance with the schedule and budget that has been set. The information system of Wedding Organizer is made with the benefits of Web-based information technology, with the aim to expand the promotion area and sales of wedding packages and facilitate the order process. This wedding organizer information system uses PHP and MySQL programming language, the method used in the development of this system is using prototyping method consisting of analysis, design, application creation, evaluation and results. The information system of Wedding Organizer is very disavit for people who do not bother with their wedding planning problems. With the development of technology nowadays wedding organizer has begun to move from online process, which is a web based wedding organizer information system.
\end{abstract}

Keywords : Wedding Information System, Web, PHP, Database MySQL

\section{PENDAHULUAN}

Perkembangan teknologi telah merambah di semua aspek kehidupan. Teknologi telah banyak membantu manusia, dan komputer merupakan alat bantu yang memberikan informasi untuk memenuhi kebutuhan. Berkembangnya teknologi informasi di bidang geografis, informasi dapat ditampilkan dengan lebih baik dan lebih cepat lewat komputer.(Ramadhani et al., 2013)

Salon Arjuna Srikandi adalah suatu perusahaan yang bergerak dibidang jasa pelayanan seperti event organizer (EO), wedding organizer (WO), entertaint dan make up artist. Namun peneliti hanya akan melakukan penelitian pada jasa pelayanan paket pernikahannya. Promosi paket pernikahan masih dilakukan melalui orang ke orang dan melalui brosur dan berdampak masih rendahnya peminat jasa paket pernikahan di Salon Arjuna Srikandi dan diperlukan media promosi lain yang baik dan dapat dilihat banyak orang. Selain itu penyebaran informasi-informasi terkait dengan paket-paket yang ditawarkan oleh Salon Arjuna Srikandi masih dilakukan melalui brosur, by phone dan sistem tersebut masih kurang efektif bagi para calon pengantin. Oleh karena itu, agar mempermudah calon pengantin untuk mencari informasi tentang paket pernikahan maka diperlukan suatu sistem yang dapat membantu calon pengantin memilih paket pernikahan sesuai yg diinginkan.

Dengan adanya sistem informasi pengadaan jasa di Salon Arjuna Srikandi maka hasil yang akan dicapai dari penelitian adalah terciptanya sebuah sistem pengadaan jasa yang dapat mempermudah pendataan calon pengantin, pembuatan laporan Salon Arjuna Srikandi, dan mempermudah calon 
pengantin dalam mengakses situs website agar mudah dalam memilih pilihan yang sesuai dengan keinginan.

\section{PENELITIAN RELEVAN}

Pendekatan penelitian berkaitan dengan tujuan utama penelitian, maka peneliti menggunakan bahan refrensi berbagai sumber, antara lai dari penelitian yang relevan dalam penelitian yang peneliti lakukan:

Penelitian oleh Fandhilah, Dany Pratmanto, A. Fatakhudin dengan judul Rancang Bangun Sistem Informasi Pemesanan Paket Pernikahan dan Preweding Berbasis Web. Hasil Penelitian adalah sistem informasi pemesanan paket pernikahan dan prewedding berbasis web, dikembangkan dengan menggunakan Adobe Dreamweaver CS5 dan MySQL sebagai basis data. Sehingga proses pengembangan website akan lebih cepat dan mudah. Perancangan Sistem Informasi Pemesanan Paket Pernikahan dan Prewedding Berbasis Web Pada Joe Art Galery adalah sebuah usaha yang bergerak di bidang wedding organizer yang ingin mengembangkan bisnis dengan memperluas lingkup pemasarannya melalui website e-commerce agar dapat menjangkau seluruh Indonesia. Selain sebagai sarana promosi online, website e-commerce dinilai memudahkan konsumen dalam proses pemesanan dan pembelian produk yang mereka inginkan sekaligus mendapatkan informasi detail produk secara cepat.(Fandhilah et al., 2015)

Penelitian oleh Hilmi Fuad, Agus Budiman, Dessy Kurniasari dengan judul Perancangan Sistem Informasi Pemesanan Paket Pernikahan Berbasis Web Study Kasus Di Wedding Organizer PJ Management. Hasil Penelitian PJ Management adalah layanan pemesanan paket di bidang perlengkapan pernikahan atau acara dimana pelanggan sangat penting hadir untuk kemajuan perusahaan. Sistem informasi pemesanan membuat wedding organizer dengan memanfaatkan informasi technology berbasis web, dengan tujuan untuk memperluas area promosi dan penjualan paket pernikahan dan mempermudah proses pemesanan. dalam pembuatan wedding organizer pemesanan sistem informasi web menggunakan pemrograman PHP dan MySQL. (Fuad et al., 2018)

\section{METODE PENELITIAN}

Metode penelitian yang digunakan oleh peneliti adalah metode grounded (grounded research) yaitu suatu metode penelitian berdasarkan fakta dan menggunakan analisis di lapangan dengan tujuan untuk mengetahui proses pengolahan data yang dilakukan selama ini. Analisis dilakukan terhadap bagian pengelola Salon Arjuna Srikandi. Peneliti bukan hanya mencari dan mengumpulkan data, tetapi juga langsung melakukan klasifikasi terhadap data tersebut, mengolah dan menganalisa data sebagai bahan untuk membuat laporan di Salon Arjuna Srikandi.

Dengan adanya permasalahan diatas, maka peneliti merancang sebuah sistem pengadaan jasa wedding berbasis web yang diharapkan dapat membantu calon pengantin dalam memilih paket pernikahan dan membantu pemilik agar mudah melakukan pendataan nama calon pengantin dan membuat laporan. Metode ini bertujuan untuk mengumpulkan informasi beserta pengumpulan data-data yang diperlukan dalam penilitan sehingga mendapatkan data-data yang akurat dan dapat digunakan untuk menunjang proses rancang bangun sistem pengadaan jasa wedding servis di Salon Arjuna Srikandi.

\section{HASIL DAN PEMBAHASAN}

\section{Analisa Permasalahan}

Prosedur kerja di Salon Arjuna Srikandi karena masih dilakukan dengan cara yang manual. Klien jasa Salon Arjuna Srikandi harus datang ke kantor langsung untuk melakukan pemesanan paket yang disebabkan keterbatasan waktu. Promosi Wedding Service masih dilakukan melalui orang ke orang dan melalui brosur dan berdampak masih rendahnya peminat jasa Wedding Service pada Salon Arjuna Srikandi dan diperlukan media promosi lain yang lebih baik dan dapat dilihat banyak orang. Berdasarkan permasalahan yang ada maka di butuhkan sistem komputerisasi seperti adanya situs website sendiri bagi Salon Arjuna Srikandi agar membantu untuk mempromosikan jasa Wedding Arjuna Srikandi.

Dari permasalahan di atas peneliti mengambil kesimpulan atas permasalahan diantaranya: 
1. Promosi masih menggunakan brosur dan informasi dari orang ke orang.

2. Calon pengantin harus ke tempat Salon Arjuna Srikandi untuk menentukan paket pernikahan.

3. Pendataan calon pengantin seperti menentukan tgl pernikahan masih menggunakan manual.

\section{Alternatif Penyelesaian}

Berdasarkan analisa sistem yang sedang berjalan saat ini peneliti melihat kelemahan-kelemahan dan pokok permasalahan yang terdapat pada Saloon Arjuna Srikandi, maka peneliti dapat menyarankan beberapa alternatif permasalahan yang dapat digunakan:

1. Membuat sistem pengadaan jasa wedding berbasis web agar calon pengantin mudah mengakses melalui internet.

2. Mempermudah dalam memilih paket pernikahan dan harga paket.

3. Mempermudah untuk pendataan calon pengantin, dan membuat laporan tiap bulannya.

\section{Diagram Konteks Diusulkan}

Diagram ini akan menjelaskan proses sistem yang akan diusulkan, sebagai berikut:

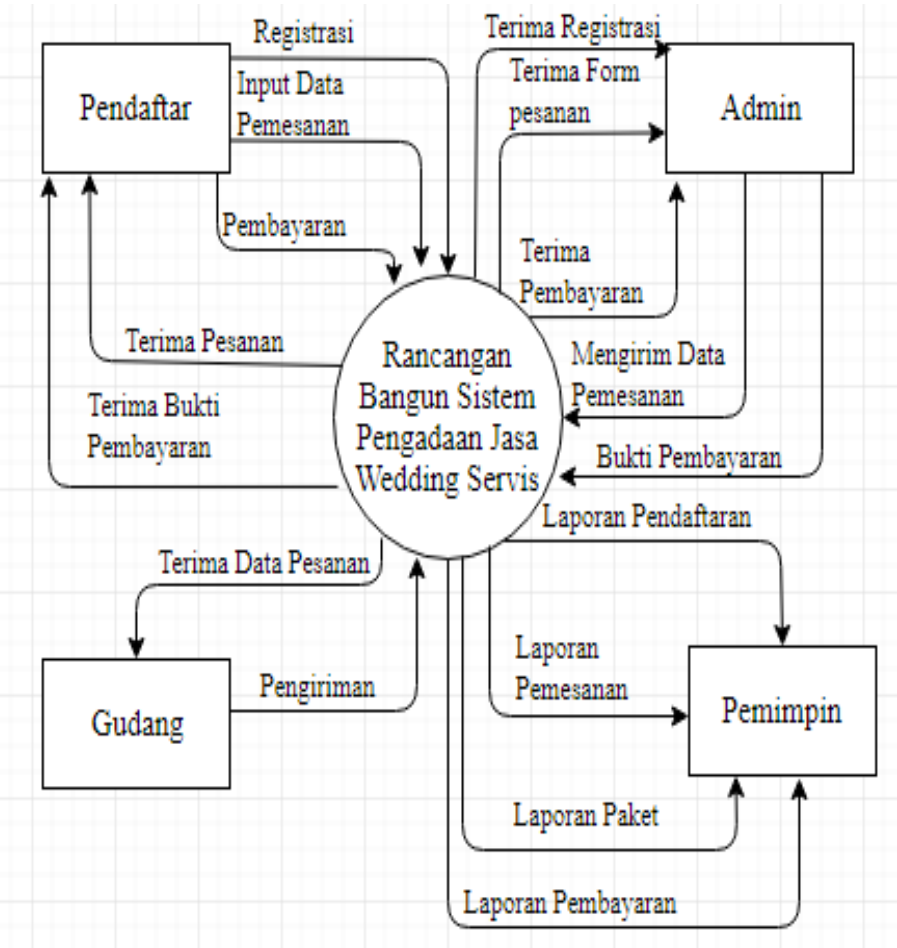

Gambar 1. Diagram Konteks Diusulkan

Diagram konteks yang diusulkan dari sistem pengadaan jasa wedding di Salon Arjuna Srikandi menggambarkan secara keseluruhan terhadap apa saja yang dilakukan oleh sistem yang akan dirancang dan siapa saja yang berhubungan dengan sistem tersebut.

Pada gambar 1 diatas dapat dilihat bahwa sistem pengadaan jasa wedding di Salon Arjuna Srikandi memiliki 4 aktor yaitu pendaftar, admin, gudang, pemimpin yang mempunya tugas dan wewenang yang berbeda-beda. 


\section{Normalisasi}

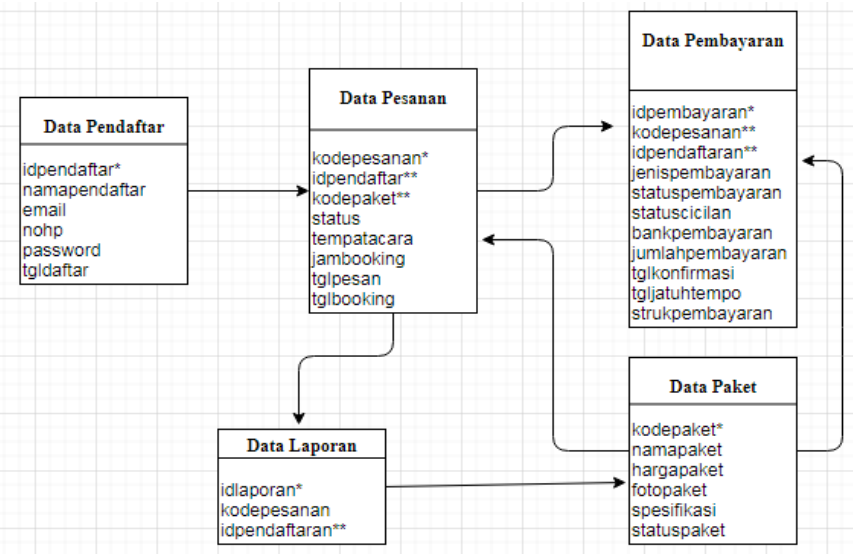

Gambar 2. Normalisasi

\section{Entity Relationship Diagram (ERD)}

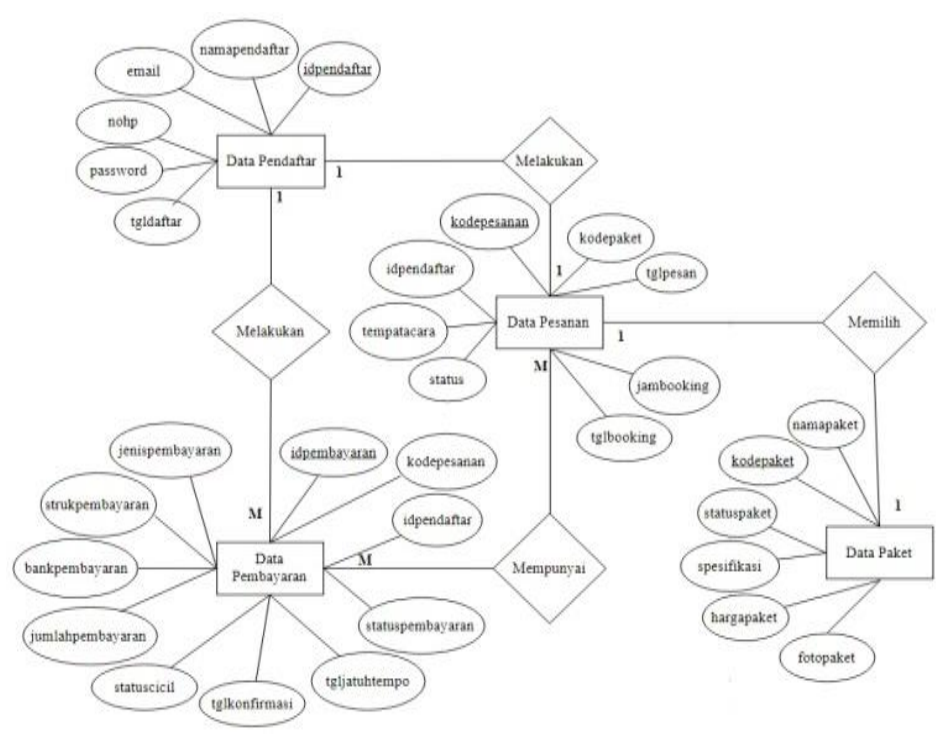

Gambar 3. Entity Relationship Diagram (ERD)

Tampilan Layar Aplikasi Sistem

Form login

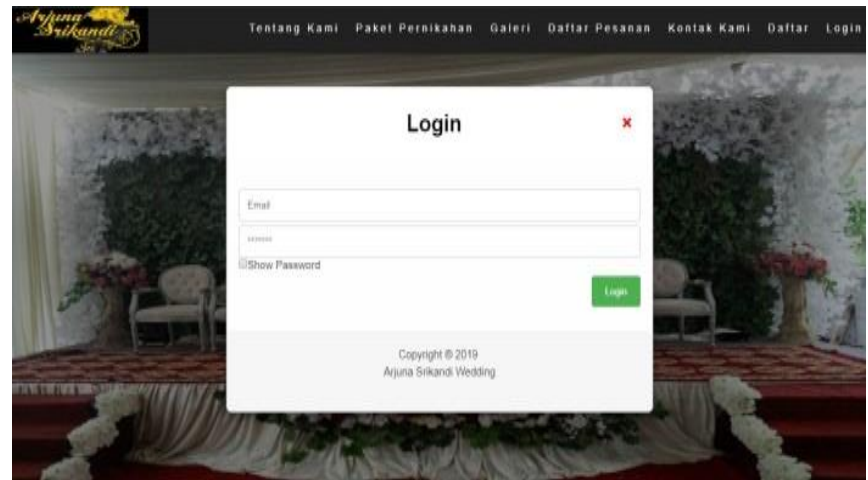

Gambar 4. Form Login

Tampilan login adalah tampilan untuk masuk ke sistem pengadaan jasa wedding dengan menginput email dan password yang telah didaftarkan 


\section{Form Menu Utama}

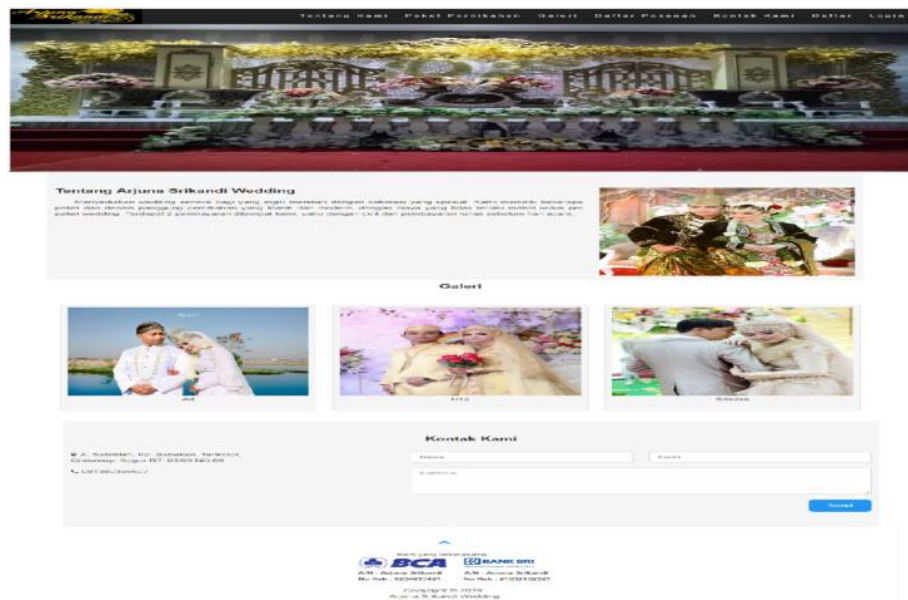

Gambar 5. Form Menu Utama

Tampilan menu utama adalah tampilan awal yang berisi menu-menu untuk proses yang akan dilakukan.

\section{Form Pemilihan Paket Wedding}

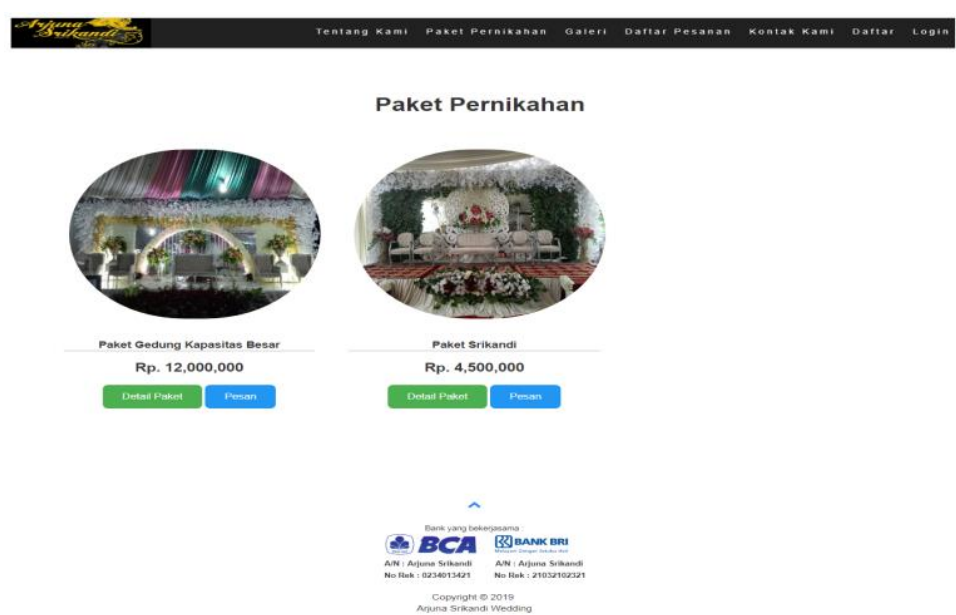

Gambar 6. Form Pemilihan Paket Wedding

Tampilan Form Pemilihan Paket Wedding adalah tampilan yang berisi data paket wedding yang dapat dipilih oleh konsumen.

\section{Form Pemesanan}

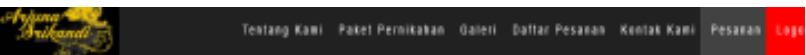

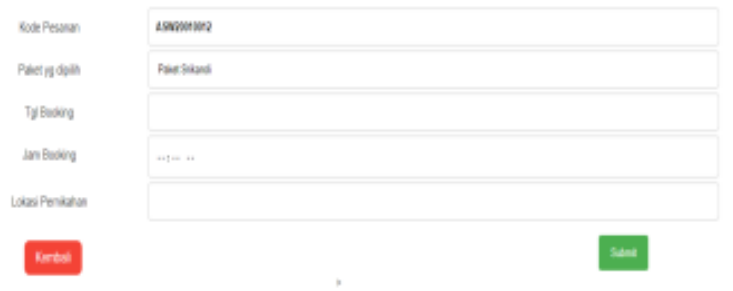


Tampilan form pemesanan tampilan untuk menginput data pesanan.

\section{SIMPULAN}

Berdasarkan hasil pembahasan mengenai "Rancang Bangun Sistem Pengadaanjasa Wedding Servis Salon Arjuna Srikandi Berbasis Web", maka peneliti menarik kesimpulan sebagai berikut:

1. Aplikasi Online Wedding Organizer Berbasis Web ini dapat memberikan informasi dan kemudahan dalam pemesanan paket wedding secara online sehingga memudah user atau calon pengantin yang sibuk dengan pekerjaannya.

2. Pada website Arjuna Srikandi ini, calon pengantin dapat melakukan pemesanan dengan memilih paket-paket yang telah tersedia maupun secara manual dan otomatis.

3. Dalam pembuatan website arjuna srikandi peneliti membuat aplikasi menggunakan bahasa pemrograman PHP dengan MySQL sebagai database.

\section{DAFTAR PUSTAKA}

Fandhilah, Pratmanto, D., \& Fatakhudin, A. (2015). Rancang Bangun Sistem Informasi Pemesanan Paket Pernikahan dan Preweding Berbasis Web ISSN : 2461-0690 ISSN : 2461-0690. Software Engineering.

Fuad, H., Budiman, A., \& Kurniasari, D. (2018). Perancangan Sistem Informasi Pemesanan Paket Pernikahan Berbasis Web Study Kasus Di Wedding Organizer PJ Management. Sisfotek Global.

Ramadhani, S., Anis, U., \& Masruro, S. T. (2013). Rancang Bangun Sistem Informasi Geografis Layanan Kesehatan Di Kecamatan Lamongan Dengan PHP MySQL. Jurnal Teknika. 